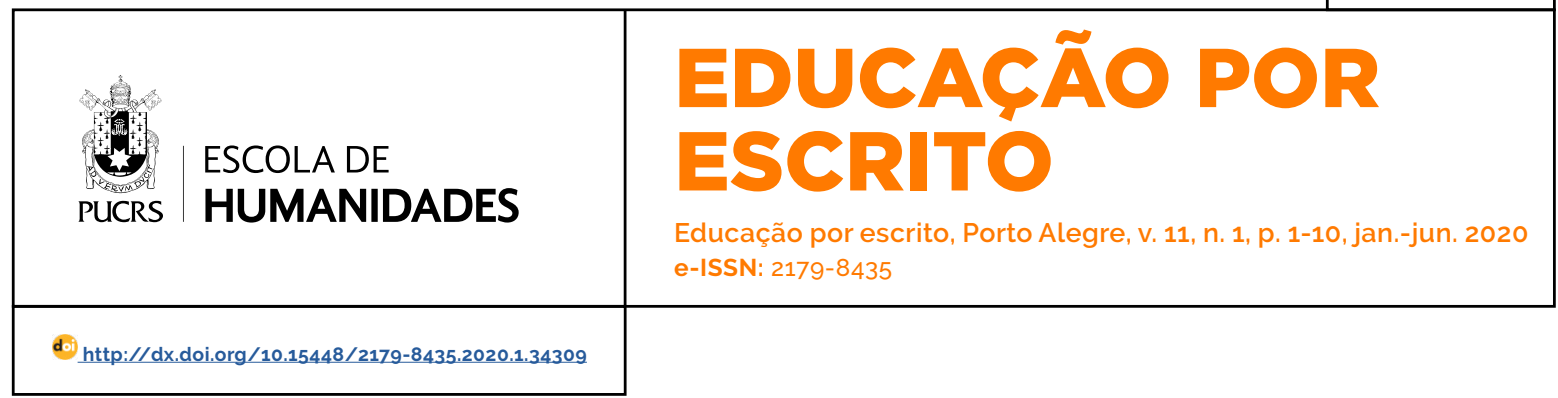

SEÇÃO: ARTIGO

\title{
Relação professor-estudante no ensino superior: uma revisão de literatura
}

\author{
Teacher-student relationship in higher education: a literature review
}

\section{Alexsandra de Santana \\ Soares Silva ${ }^{1}$ \\ orcid.org/0000-0001-8725-2443 \\ alexssa_silva@hotmail.com}

\section{Marinalva Lopes \\ Ribeiro $^{1}$}

orcid.org/0000-0002-9197-1341 marinalva-biodanza@hotmail.com

Recebido em: 29 mai. 2019. Aprovado em: 1 ago. 2020. Publicado em: 27 jul. 2020.

\section{(c) (1)}

Artigo está licenciado sob forma de uma licença Creative Commons Atribuição 4.0 Internacional.
Resumo: Este artigo busca discutir questões acerca da relação professor-estudante e a sua relevância para a adaptação e o desenvolvimento acadêmico. Trata-se de uma revisão de literatura nos bancos de dados da Associação Nacional de Pós-Graduação e Pesquisa em Educação; da Coordenação de Aperfeiçoamento de Pessoal do Nivel superior; de Periódicos Eletrônicos de Psicologia; e da Scientific Eletronic Library Online, no periodo de 2010 a 2018, a partir dos descritores "relação professor-aluno", "professor-estudante" e "afetividade no ensino superior". O objetivo consistiu em compreender como acontece a relação professor-estudante e a importância dessa no processo de adaptação e desenvolvimento do universitário. Os resultados revelaram que a relação professor-estudante precisa ser construída com base no diálogo, na troca de experiências, na afetividade e, também, que uma boa relação entre professor e estudante pode ser útil como fator protetor para os discentes que apresentam dificuldades na aprendizagem, bem como motivadora para aqueles que não apresentam tais dificuldades.

Palavras-chave: Relação professor-estudante. Pedagogia universitária. Adaptação do estudante.

Abstract: This article seeks to discuss questions about the teacher-student relationship and its relevance to academic adaptation and development. This is a literature review in the National Association of Postgraduate and Research in Education databases; Coordination of Improvement of Higher Education Personnel; Electronic Psychology Journals; and Scientific Eletronic Library Online in the period from 2010 to 2018, using the descriptors "teacher-student relationship", "teacher-student" and "affectivity in higher education". The objective was to understand how the teacher-student relationship happens and its importance in the university's adaptation and development process. The results revealed that the teacher-student relationship needs to be built based on dialogue, exchange of experiences, affectivity and also that a good relationship between teacher and student can be useful as a protective factor for students who have difficulties in learning, as well as motivating for those who don't present such difficulties. Keywords: Teacher-student relationship. University Pedagogy. Student adaptation.

\section{Introdução}

O interior de uma universidade é permeado por múltiplas relações interpessoais, sendo possivel destacar a relação professor-estudante como uma das mais importantes (ANUNCIAÇÃO; ANTÓNIO; MANUEL, 2015). Isso possivelmente ocorre porque, embora esteja sujeita a um programa e a normas da instituição de ensino, a interação entre professor e estudante forma o centro do processo educativo.

Sabemos que não são poucos os fatores que influenciam as relações 
entre os estudantes e o professor. Entretanto, a visão sobre o papel da educação que o professore os estudantes possuem torna-se uma orientação essencial para o trabalho desenvolvido (PORTO; SOARES, 2017). Segundo Freire (1987), a educação deve estar a serviço da humanização das pessoas, já que é uma forma de intervenção no mundo.

De acordo com Guimarães et al. (2011), os estudantes que ingressam no ensino superior se deparam com diversas situações novas e desafiadoras em suas vidas. Dentre elas, destacam-se: a dificuldade de adaptação à universidade; o afastamento dos familiares e dos amigos, nos casos em que o estudante precisa mudar de cidade; e a relação pessoal e interpessoal face às novas amizades, aos professores, ao ambiente acadêmico e ao estudo.

A adaptação à universidade é um entrelaçamento entre fatores sociais, pessoais e institucionais que levam o estudante a integrarse satisfatoriamente ao curso e à instituição. Assim, as relações interpessoais com a familia, com os pares e com os docentes podem facilitar a ambientação ao ensino superior, ao curso e à instituição escolhida (SOARES; DEL PRETTE, 2015).

Acerca da relação professor-estudante no ensino superior, Masetto (2012) assinala ser incoerente assumir uma atividade de docência sem se aprofundar no conhecimento e na prática de uma relação que colabore para a aprendizagem. E, para tanto, destaca que o papel tradicional do professor que transmite informações e conhecimentos a seus alunos necessita de uma revisão.

Dessa forma, Masetto (2012, p. 60) ressalta:

É importante que o professor desenvolva uma atitude de parceria e corresponsabilidade com os alunos, que planejem o curso juntos, usando técnicas em sala de aula que facilitem a participação e considerando os alunos como adultos que podem se corresponsabilizar por seu periodo de formação profissional.

A afirmação acima evidencia a importância de o professor do ensino superior ser um sujeito acessivel aos estudantes e utilizar seus conhecimentos científicos, didáticos e filosóficos em ação, para fazer seu papel de mediador, contribuindo para uma formação de qualidade (SÔNEGO, 2015).

A partir disso, este artigo apresenta como problemática fundamental a importância que a relação estabelecida entre professor e estudante do ensino superior possui para a vida acadêmica do universitário. Visa-se responder à seguinte pergunta norteadora: Qual a importância da relação professor-estudante no processo de adaptação e desenvolvimento acadêmico do discente?

Assim, o objetivo é compreender como acontece a relação professor-estudante e a importância desta no processo de adaptação e desenvolvimento do universitário.

Identifica-se, neste estudo, a perspectiva de contribuir para o estímulo do planejamento e da implementação de políticas institucionais na universidade que visem ao desenvolvimento profissional dos professores universitários, de modo que o ambiente em sala de aula seja pautado na confiança e no empenho conjunto para uma aprendizagem significativa.

Assim, considera-se que o conhecimento a ser produzido poderá trazer contribuições, tanto para melhor compreender a relação entre os estudantes e os professores da educação superior, quanto para perceber a relevância dessa na adaptação e no desenvolvimento acadêmico de tais sujeitos.

\section{Procedimentos metodológicos}

A revisão de literatura sobre "relação professorestudante" foi realizada a partir do levantamento de trabalhos empíricos e teóricos durante os meses de fevereiro e março de 2019, nas seguintes bases de dados: a) Associação Nacional de PósGraduação e Pesquisa em Educação (Anped) no GT8; b) Coordenação de Aperfeiçoamento de Pessoal do Nivel superior (Capes); c) Periódicos Eletrônicos de Psicologia (Pepsic); e d) Scientific Eletronic Library Online (Scielo Brasil).

Para a realização do levantamento, utilizaramse os descritores: "relação professor-aluno"; "professor-estudante" e "afetividade no ensino superior". Como critério de inclusão foi adotado o recorte temporal das publicações mais recentes, ou seja, dos últimos nove anos, que compreendeu o período de 2010 a 2018. Além disso, os 
estudos teriam que ser empíricos, de revisão ou ensaios teóricos, constituídos de resumos que apresentassem método, resultados e discussão.

Os estudos encontrados deveriam apresentar resultados que tivessem associação da relação professor-estudante com o ensino superior. Como critério de exclusão, não foram considerados artigos que possuíssem vínculo dessa relação com os sujeitos da Educação Básica. Não foram considerados, também, os artigos duplicados entre as bases de dados e aqueles que não disponibilizavam o resumo ou texto completo.
Todos os estudos que atenderam aos critérios estabelecidos foram selecionados e organizados em tabelas a partir das variáveis: ano de publicação, título, objetivo, métodos e resultados. Esse processo favoreceu a leitura flutuante dos artigos possibilitando a configuração de categorias para fomentar a discussão do presente artigo.

Na pesquisa realizada, foram encontrados 217 trabalhos nos gêneros tese, dissertação e artigo, sendo selecionados 20 trabalhos que contemplavam os critérios seguidos, conforme apresentado no Quadro 1.

Quadro 1 - Composição dos trabalhos selecionados

\begin{tabular}{|c|c|c|c|c|}
\hline BASE DE DADOS & $\begin{array}{l}\text { TRABALHOS } \\
\text { ENCONTRADOS }\end{array}$ & \multicolumn{3}{|c|}{ TRABALHOS SELECIONADOS } \\
\hline CAPES & 200 & 2 & 10 & -------- \\
\hline Scielo & 10 & --------- & --------- & 7 \\
\hline ANPED & 4 & --------- & -------- & -------- \\
\hline
\end{tabular}

Fonte: Elaborado pelas autoras.

A partir dos descritores "relação professoraluno", "professor-estudante" e "afetividade no ensino superior" na base de dados da CAPES foram encontrados 200 trabalhos e selecionadas 2 teses e 10 dissertações. Na base de dados do Scielo, foram encontrados 10 estudos $e$ selecionados 7 artigos. No portal da ANPED, foram encontrados 4 trabalhos, mas nenhum foi selecionado. Na base PePSIC foram encontrados 3 artigos e selecionado 1 artigo.

Em relação ao ano de publicação dos estudos (teses, dissertações e artigos) localizados, 4 foram publicados em 2010; 4 no ano de 2011, 2 no ano de 2012; 1 no ano de 2014; 1 no ano de 2015, 2 no ano de 2016; 5 no ano de 2017; e 1 no ano de 2018.

Ressalta-se que essas produções abordam a relação professor-estudante na universidade nas mais variadas perspectivas. Surgem, nesse contexto, como temáticas privilegiadas as discussões e investigações voltadas à influência das interações entre professores e estudantes no contexto da sala de aula, nas atividades práticas diante dos pacientes e no percurso de desenvolvimento e formação dos educandos.

Entretanto, no que se refere à relação professor-estudante nos cursos das ciências tidas como hard (dura), ciências exatas, como é o caso da graduação de engenharia, percebe-se que existe um número reduzido de pesquisas, sendo prioridade, nesse contexto, o estudo com as licenciaturas, as ciências sociais e saúde.

Os locais de origem em que foram realizados os estudos (teses, dissertações e artigos) estão assim distribuidos: Portugal, dois (Coimbra, 1 e Braga,1) e Brasil, dezoito (Rio de Janeiro,1; São Paulo, 5; Minas Gerais, 2; Espírito Santos,1; Rio Grande do Sul, 1; Brasília,1; Bahia, 4; Recife,1; Maranhão, 1; Manaus,1). Esses dados demonstram, 
que no Brasil, as referências selecionadas na presente revisão de literatura apresentam maior representatividade na região sudeste.

\section{Resultados e discussão}

Foram selecionados para este estudo 20 (vinte) trabalhos que discutem sobre a relação professor-estudante na educação superior. Dessas pesquisas foram obtidas informações a partir das variáveis: ano de publicação, titulo, autor(es) e objeto de estudo, conforme Quadro 2.

Quadro 2 - Estudos selecionados a partir das variáveis ano de publicação, título, autor(es) e objeto de estudo

\begin{tabular}{llll}
\hline $\begin{array}{l}\text { ANO DE } \\
\text { PUBLICAÇÃo }\end{array}$ & TÍTULO & AUTOR(ES) & OBJETO DE ESTUdO \\
\hline
\end{tabular}

2018

De quem é a universidade? um estudo sobre a relação de poder na interação aluno-professor

Rayanne Linhares Azevedo

A influência da relação afetiva entre professores 2017 e estudantes do curso de educação física da UEFS no processo de formação acadêmica

Representações sociais de Afetividade na relação professor-aluno: uma pesquisa bibliográfica exploratória

Relações interpessoais na 2016 universidade: o que pensam estudantes da graduação em psicologia?

Relação afetiva entre pro2016 fessora e estudantes do ensino superior: sentidos, desafios e possibilidades

Relação professor-aluno te: representações sociais
Clebson dos Santos Mota

Esther Cosso

Walkiria Carvalho Pereira da Silva

Flavia Regina de Barros

Alexandre Britto Pereira

Adriana Benevides Soares et al.

Cleudinéte Ferreira dos Santos Souza

Edilene Freitas Silva de Almeida construidas

Concepção de estudantes e professores de licenciatura sobre a relação de poder na interação aluno-professor na universidade.

Influência da relação afetiva entre professores e estudantes do curso de Educação Física no processo de formação acadêmica.

As representações sociais de professores e alunos do ensino superior sobre a relação professor aluno.

As concepções e as ações que interferem de forma positiva ou negativa no processo de ensino-aprendizagem dos discentes.

Impactos afetivos, positivos ou negativos, nas relações que se estabelecem entre os alunos e os conteúdos de ensino abordados.

Estudos referentes à afetividade, especificamente no contexto da relação professor-aluno.

Percepções de estudantes universitários suas vivências em situações interpessoais no espaço acadêmico

Relação afetiva entre docente e estudantes na prática de ensino, tendo como referências as suas representações sociais.

Relação professor-aluno na formação inicial docente e em sua prática profissional a partir dos elementos constituintes das representações sociais dos licenciados em Letras. 


\section{ANO DE TÍTULO \\ AUTOR(ES) \\ OBJETO DE ESTUDO \\ PUBLICAÇÃO}

Percepções de estudantes

2014 universitários sobre a relação professor-aluno

A relação entre professor e

2012 aluno no ensino superior vista por meio da reprovação

Relação professor e aluno no ensino superior: reflexões no contexto de formação de professores de educação física

O bom professor: opinião dos estudantes

Aprendizagem e relação pro2011 fessor-aluno na universidade: duas faces da mesma moeda

Estudo das interações

2011 sociais entre professores e alunos no ensino superior

Uma relação delicada:

2011 estudo do encontro professor-aluno

Percepções de alunos de excelência relativamente

2010 ao papel dos professores: um estudo com alunos de engenharia

A afetividade na relação professor-aluno e suas implicações na aprendizagem em contexto universitário

A afetividade na relação educativa

A relação professor-aluno no ensino da odontologia na universidade Federal do Espirito Santos
Marinalva Lopes Ribeiro
Clarissa Tochetto de Oliveira et al

Daniel Gonçalves Cury Aroeira e Francyne Wolkartte Merlo

Maria Clara Amado Apóstolo Ventura et al.

Cenilza Pereira dos Santos e Sandra Regina Soares

Micherlângela Barroso Rocha

Izabel Cristina Rios e Lilia Blima Schraiber

Silvia Monteiro, Leandro S. Almeida José Fernando A. Cruz e Rosa M. Vasconcelos

\section{ras e Sandra Patrícia Ataide Ferreira \\ Renata da Silva Ve-}

Kalline Pereira

Percepções de universitários sobre sua relação com os professores e a influência dessa percepção em sua adaptação acadêmica.

As relações entre docentes e alunos por meio da reprovação e suas influências na formação profissional durante a graduação.

As concepções de estudantes de Educação Física sobre a relação professor e aluno no âmbito de sua formação.

Opinião dos estudantes sobre o perfil de um bom professor.

As representações sobre a relação professor-aluno no processo formativo na universidade.

Qualidade das interações sociais envolvidas no contexto da sala de aula do ensino universitário

O encontro intersubjetivo de professores e alunos, ressaltando aspectos referidos à cultura contemporânea.

Percepção de cinco alunos de excelência em cursos de engenharia sobre a influência dos professores no seu percurso de desenvolvimento e formação.

A postura do professor em sala de aula e as implicações sobre a experiência de aprendizagem positiva de estudantes universitários.

As características dos professores em exercício no Brasil, a falta de inter-relação entre os aspectos cognitivos, emocionais e afetivos e a insuficiência de obras relativas à afetividade na relação educativa.

Aline Guio Cavaca

A relação professor-aluno no curso de odontologia.

Fonte: Elaborado pelas autoras.

Alimentado o Quadro 1, as informações dos resultados obtidos foram agrupadas em 4 (quatro) categorias baseadas nas reflexões e nas temáticas abordadas, fomentando a discussão do presente 
estudo acerca da relação professor-estudante no ensino superior. As categorias foram assim denominadas: a) a influência das características profissionais docentes na relação professorestudante; b) a influência das características pessoais do docente na relação professorestudante; c) a influência de uma relação amistosa na relação professor-estudante; e d) o ambiente/ clima de aprendizagem como fator protetor dos estudantes ingressantes.

a) a influência das características profissionais docentes na relação professor-estudante: estudos identificaram que as caracteristicas profissionais, ou seja, os aspectos referentes à formação, à didática e à prática pedagógica de professores universitários podem constituir elementos que favoreçam ou não o processo de adaptação e desenvolvimento do estudante (OLIVEIRA et al., 2014; MONTEIRO et al., 2010; SOARES et al., 2016; AROEIRA e MERLO, 2012).

Dessa forma, por um lado, a relação entre docente e discente pode facilitar a adaptação do estudante ao ensino superior, através da didática que envolve o desempenho do docente em sala de aula, a competência e a capacidade de ensinar. Por outro lado, pode fazer com que estudantes vivenciem sentimentos de decepção, de forma que a sua impressão sobre a universidade deixa de ser tão positiva (OLIVEIRA et al., 2014).

Nessa linha, Soares et al. (2016) argumentam, a partir de pesquisas realizadas com estudantes de psicologia, que o professor que utiliza técnicas incompativeis com as formas de aprendizado dos estudantes faz com que estes se sintam excluídos, podendo resultar em um distanciamento das capacidades e do interesse dos discentes em aprender a matéria.

Pereira (2017) afirma que a relação professorestudante apresenta correspondência direta com a qualidade do processo ensino-aprendizagem. $\mathrm{E}$, a qualidade da mediação docente pode produzir afetos positivos ou negativos nesse processo, dessa forma, a afetividade não pode ser pensada isolada da cognição.
Diante do exposto, é possivel inferir que a afetividade qualifica a relação que se estabelece entre docente e discente, o que implica em uma melhor qualidade da mediação e, consequentemente, uma maior qualidade no aprendizado e na adaptação acadêmica.

Essas pesquisas apontam que as relações estabelecidas na universidade entre professores e estudantes, a depender das caracteristicas profissionais dos docentes, assumem papel importante na compreensão da qualidade da experiência universitária;

\section{b) a influência das características pes- soais do docente na relação profes- sor-estudante: além das caracteristicas profissionais do docente destacou-se também, nas pesquisas levantadas, as caracteristicas pessoais do professor (BARROS, 2017; MOTA, 2017; SOUZA, 2016; OLIVEIRA et al., 2014; MONTEIRO et al., 2010) como um dos aspectos da relação professor-estudante que pode interferir no processo de adaptação e, sobretudo, no desenvolvimento acadêmico.}

As caracteristicas pessoais fazem referência aos aspectos afetivos presentes no modo de ser do docente na relação professor-estudante. Na pesquisa realizada por Monteiro, Cruz e Vasconcelos (2010), com alunos de excelência, o autor destacou que, para esses estudantes, o papel dos docentes vai além da figura que transmite conhecimentos, associando a essa função mais "óbvia" do professor aspectos afetivos e relacional.

Ribeiro (2010) enfatiza que a afetividade é importante na relação educativa, pois é pelo caminho afetivo que as aprendizagens cognitivas dos estudantes se constroem. Logo, o docente não pode se descuidar dos sentimentos e emoções imbricados em sua prática educativa, visto que a demonstração de interesse, cuidado e preocupação, por parte do professor, o porquê e como acontecem os processos produtivos do conhecimento na mente dos estudantes podem transformar a dificuldade de aprender desses sujeitos em melhores resultados acadêmicos e formativos. 
Souza (2016) e Mota (2017) revelam, com seus estudos, que o professor afetivo é próximo, solidário, acolhedor, preocupa-se com as necessidades formativas dos estudantes, respeita as diferenças culturais, dedica-se à profissão, é amigo, tem sensibilidade, flexibilidade e humanidade ao tratar das dificuldades cognitivas e afetivas dos estudantes. Além de tais características pessoais, Ribeiro (2005) acrescenta que o professor afetivo é humano, afetuoso, paciente, pacífico, compreensivo, humilde, empático, estudioso, respeitoso, confiante, aberto às críticas e ao diálogo. Ademais, percebe as necessidades dos estudantes e coloca-se à disposição para ajudá-los;

c) a influência de uma relação amistosa na relação professor-estudante: o distanciamento entre professores e estudantes, a falta de abertura de alguns docentes e à dificuldade de um relacionamento mais próximo com os estudantes são fatores apontados em estudos como o de Azevedo (2018), Oliveira et al. (2014) e Cavaca et al. (2010) que podem influenciar negativamente o processo de ensino e aprendizagem.

Santos e Soares (2011), sobre a relação entre professores e estudantes no curso de Pedagogia, sinalizaram que contempla, de um lado um discurso idealizado acerca do papel do professor, como mediador da aprendizagem e da participação ativa e comprometida do estudante e, de outro, práticas estudantis baseadas na heteronomia, no medo de se expor e ser repreendido pelo professor. Essa significação construida durante as vivências escolares foi reforçada pelas práticas vivenciadas na universidade que se distanciaram pouco das experiências anteriores e, dessa forma, não contribuíram, efetivamente, para a ressignificação de tais representações.

Aroeira e Merlo (2012) identificaram na pesquisa realizada com estudantes de educação física que a relação interpessoal entre professor e estudante é um importante fator interveniente no processo de ensino e aprendizagem. Mais de $80 \%$ dos participantes dessa pesquisa afirmaram que é necessário, além da qualificação docente, que os professores sejam compreensivos e mantenham uma relação agradável com os alunos e com a turma, pois, assim, eles se sentem à vontade para expor suas opiniões e questionar sobre suas dúvidas.

Cosso (2017) apontou em seu estudo que o tipo de relacionamento entre o docente e o discente pode predizer positivamente a autoestima e prever negativamente casos de depressão em comportamentos problemáticos. Assim, a relação positiva entre o professor e o estudante pode servir como fator protetor para os alunos que apresentam dificuldades para aprender e motivador para os que não apresentam tais dificuldades.

No estudo conduzido por Cavaca et al. (2010) com estudantes de odontologia, evidenciouse que uma relação docente-discente de qualidade, isto é, pautada no respeito mútuo, no estímulo à comunicação entre docentes, alunos e pacientes e na ausência de atitudes coercitivas dos professores, pode representar um maior aproveitamento do aluno e a incorporação de valores essenciais para o exercício de uma odontologia humanizada.

Dessa forma, observa-se nesses estudos que a falta de uma relação amistosa entre professor e estudante, ou seja, o relacionamento distante entre esses sujeitos pode acarretar consequências negativas para a vida acadêmica, favorecer o abandono do curso (OLIVEIRA et al., 2014) e contribuir para o processo de evasão da universidade (BARDAGl; HUTZ, 2012);

d) o clima de aprendizagem como fator protetor dos estudantes ingressantes: além dos aspectos relacionados às caracteristicas profissionais e pessoais dos docentes, a relação amistosa na relação professor-estudante, nas pesquisas apresentadas, os aspectos específicos do clima propício para o ensino e a aprendizagem também aparecem como determinantes para o investimento e desenvolvimento dessa relação.

A importância da relação dos professores e estudantes se estabelece de forma agradável 
em sala de aula, qualificando o processo de ensino-aprendizagem e a necessidade dessa relação estar baseada nos aspectos afetivos, motivacionais, científicos e morais, fatores essenciais levantados no estudo de Aroeira e Merlo (2012) para a consignação de um ambiente favorável nessa relação.

Os resultados da pesquisa de Almeida (2015) apontam que as representações sociais vivenciadas e/ou construidas no cotidiano da sala de aula ou em fase anterior exercem influência na aprendizagem do aluno, bem como repercutem na prática profissional. Assim, por ser essa relação essencialmente interativa, requer um espaço dialógico em que representações formadas ou em formação respaldam-se no respeito e confiança, criando um ambiente para o desenvolvimento do processo ensino-aprendizagem.

Nessa veia de raciocínio, Boruchovitch e Bzuneck (2001) evidenciam que o ambiente instrucional se torna fonte de influência para o envolvimento do estudante com a aprendizagem. Desse modo, torna-se relevante a natureza das tarefas, a maneira de o professor avaliar, a autonomia propiciada, dentre outras variáveis que caracterizam o clima favorável para o estudante no momento de adaptação ao ambiente universitário.

Oliveira (2014) destaca a necessidade de os docentes atuarem tanto no nível teóricodidático quanto no nivel interpessoal, mostrandose abertos ao diálogo e preocupados com a adaptação acadêmica e formação dos discentes, auxiliando-os na orientação quanto à carreira que uma interação professor-estudante de qualidade está associada com a adaptação e com o desenvolvimento acadêmico.

\section{Considerações finais}

Diante da análise das pesquisas aqui apresentadas, observa-se que a relação professorestudante precisa ser construida com base no diálogo, na troca e na afetividade. Nesse sentido, é possivel inferir que uma boa relação entre professorestudante pode servir como fator protetor para os alunos que apresentam dificuldades para aprender e motivador para os que não apresentam tais dificuldades (COSSO, 2017).

A relação professor-estudante, além de ser um elemento significativo para o processo de ensino e aprendizagem, pode ser, também, para a adaptação do estudante que ingressa na universidade.

Dessa forma, nota-se a importância de os docentes atuarem tanto no nível teórico-didático, quanto no nivel interpessoal, mostrando-se abertos ao diálogo e atentos à adaptação acadêmica e à formação dos discentes, auxiliando-os tanto na orientação quanto na carreira.

Acreditamos que este estudo oportuniza a produção de outras pesquisas que abranjam esse tema, como a busca do desenvolvimento profissional dos professores universitários, de modo que o ambiente em sala de aula seja pautado na confiança e no empenho conjunto para uma aprendizagem significativa.

\section{Referências}

ALMEIDA, Edilene Freitas Silva de. Relação professor-aluno na formação inicial docente: representações sociais construidas. 2015. Dissertação (Mestrado em Educação) - Universidade Federal do Maranhão, São Luís, 2015

ANUNCIAÇÃO, Luisa da; ANTÓNIO, David; MANUEL, Janice Alexandra da Costa. Importância da Relação Professor-Aluno na Educação Superior. In: CONGRESSO NACIONAL DE EDUCAÇÃO: FORMAÇÃO DE PROFESSORES, COMPLEXIDADE E TRABALHO DOCENTE, 11., 2015, Prado velho. Anais... Prado velho, 2015. P. 1-10

AROEIRA, Kalline Pereira; MERLO, Francyne Wolkartte. Relação professor e aluno no ensino superior reflexões no contexto de formação de professores de Educação Física. In: XVI ENDIPE - ENCONTRO NACIONAL DE DIDÁTICA E PRÁTICAS DE ENSINO UNICAMP, Campinas, 2012.

AZEVEDO, Rayanne Linhares. De quem é a Universidade? Um estudo sobre a relação de poder na interação aluno-professor. 2018. 152f. Dissertação (Mestrado em Processos de Desenvolvimento Humano e Saúde) - Universidade de Brasília, Brasilia, 2018.

BARDAGI, M. P.; HUTZ, C. S. Mercado de trabatho, desempenho acadêmico e o impacto sobre a satisfação universitária. Revista de Ciências Humanas, 40, p. 183-198, 2012. https://doi.org/10.5007/ 2178-4582.2012V46n1p183

BARROS, Flávia Regina. Impactos afetivos das práticas pedagógicas no ensino superior: o olhar dos alunos. 2017. 278f. Tese (Doutorado em Educação) - Universidade Estadual de Campinas, Faculdade de Educação, Campinas, SP, 2017. 
BORUCHOVITCH, Evely; BZUNECK, José Aloyseo. A motivação do aluno: contribuições da Psicologia Contemporânea. Petrópolis, RJ: Vozes, 2001.

CAVACA, Aline Guio et al. A relação professor-aluno no ensino da Odontologia na Universidade Federal do Espírito Santo. Trab. educ. saúde, Rio de Janeiro, v. 8, n. 2, p. 305-318, 2010. Disponivel em: http://www.scielo.br/scielo.php?script=sci_arttext\&pid=S1981=77462010000200008-\&lng=en\&nrmiso. Acesso em: 14 Jan. 2019. http://dx.doi. org/10.1590/S1981-77462010000200008.

COSSO, Esther. Representações sociais de professores e alunos do ensino superior sobre relação professor e aluno. 2017. 89f. Tese (Doutorado em Psicologia Educacional) - Centro Universitário Fieo, Osasco, 2017.

CURY, Daniel Gonçalves. A relação entre professor e aluno no ensino superior vista por meio da reprovação. 2012. Dissertação (Mestrado em Psicologia) Universidade Federal de Uberlândia, Uberlândia, 2012.

FREIRE, P. Pedagogia do oprimido. 17. ed. Rio de Janeiro: Paz e Terra, 1987.

GUIMARÃES, L. A. C. et al. Relação entre dados sociodemográficos e vivências acadêmicas: aspectos psicossociais. Trabalho apresentado no Décimo Sexto Encontro Nacional de Psicologia Social da ABRAPSO, Recife, PE. Disponivel em: http://www. encontro2011.abrapso.org.br/site/textoscompletos.

MASETTO, Marcos Tarcísio. Competência pedagógica do professor universitário. 2. ed. rev. São Paulo: Summus, 2012.

MONTEIRO, S. et al. Percepções de alunos de excelência relativamente ao papel dos professores: um estudo com alunos de engenharia. Revista Portuguesa de Educação, v. 23, n. 2, p. 213-236, 2010. https://doi.org/10.21814/rpe.13993

MOTA, Clebson dos Santos Mota. A influência da relação afetiva entre professores e estudantes do curso de educação física da UEFS no processo de formação acadêmica. 2017. 154f. Dissertação (Mestrado em Educação) - Universidade Estadual de Feira de Santana, Feira de Santana, 2017.

MUNIZ, Micheriângela Barroso. Estudo das interações sociais entre professores e alunos no ensino superior. 2011. 67f. Dissertação (Mestrado em Educação) Universidade Federal do Amazonas, Manaus, 2011.

OLIVEIRA, Clarissa Tochetto de et al. Percepções de estudantes universitários sobre a relação professor-aluno. Psicol. Esc. Educ., v.18, n. 2, p. 239-246, 2014. ISSN 1413-8557. https://doi.org/10.1590/2175$3539 / 2014 / 0182739$

PEREIRA, Alexandre Britto. Afetividade na relação professor-aluno: uma pesquisa bibliográfica exploratória. 2017. 144f. Dissertação (Mestrado em Psicologia) - Universidade Federal de Minas Gerais, Belo Horizonte, 2017.
PORTO, Ana Maria da Silva; SOARES, Adriana Benevides. Diferenças entre expectativas e adaptação acadêmica de universitários de diversas áreas do conhecimento. Aná. Psicológica, Lisboa, v. 35. n. 1, p. 13-24, mar. 2017. Disponivel em: http:// www.scielo.mec.pt/scielo.php? script=sci_arttext\&pid $=S 0870=82312017000100002-\&$ lng $=$ pt\&nrmiso. Acesso em: 22 maio 2019. https://doi. org/10.14417/ap.1170

RIBEIRO, M. L.; JUTRAS, F.; LOUIS, R. Análise das representações sociais de afetividade na relação educativa. Psicologia da Educação, São Paulo, v. 20, n. 1, p. 1-163, 2005

RIBEIRO, M. L. A afetividade na relação educativa. Estud. psicol., Campinas, v. 27, n. 3, p. 403-412, set. 2010. ISSN 0103-166X. https://doi.org/10.1590/ S0103-166X2010000300012

RIOS, I.C.; SCHRAIBER, L.B. Uma relação delicada: estudo do encontro professor-aluno. Interface, Botucatu, v. 15, n. 36, p. 39-52, 2011. https://doi. org/10.1590/S1414-32832010005000038

SANTOS, C. P.; Soares, S. R. Aprendizagem e relação professor-aluno na universidade: Duas faces da mesma moeda. Estudos em Avaliação Educacional, v. 22, n. 49, p. 353-369. Disponivel em: http://www.fcc.org.br/pesquisa/publicacoes/eae/ arquivos/1641/1641.pdf. https://doi.org/10.18222/ eae224920111980

SILVA, W. C. P. da. Representações sociais de professores do ensino superior sobre relação professor-aluno: um estudo de caso. 2017. Dissertação (Mestrado em Psicologia Educacional) - Centro Universitário Fieo, Osasco, 2017.

SOARES, Adriana Benevides et al. Relações interpessoais na universidade: o que pensam estudantes da graduação em psicologia?. Est. Inter. Psicol., Londrina, v. 7. n. 1, p. 56-76, jun. 2016. Disponivel em: http://pepsic.bvsalud.org/scielo.php?script=sci_arttext\&pid=S2236-64072016000100005\&lng =pt\&nrm =iso. Acesso em: 20 mar. 2019

SOARES, Adriana Benevides; DEL PRETTE, Zilda Aparecida Pereira. Habilidades sociais e adaptação à universidade: Convergências e divergências dos construtos. Aná. Psicológica, Lisboa, v. 33, n. 2, p. 139-151, jun. 2015. Disponivel em: http://www. scielo.mec.pt/scielo.php?script=sci_arttext\&pi$\mathrm{d}=50870-82312015000200001 \& \mathrm{lng}=$ pt\&nrm=iso. Acesso em: 07 fev. 2019. http://dx.doi.org/10.14417/ap.911.

SÔNEGO, Aline. Os desafios da universidade no século XXI e algumas reflexões sobre a posição docente frente a este processo. Revista Brasileira de Ensino Superior, v. 1, n. 1, p. 30-35, 2015. Disponivel em: https://seer.imed.edu.br/index.php/REBES/ article/view/822. Acesso em: 23 abr. 2019.

SOUZA, Cleudinéte Ferreira dos Santos. Relação afetiva entre professora e estudantes do Ensino Superior: sentidos, desafios e possibilidades. 2016. 171f. Dissertação (Mestrado em Educação) - Universidade Estadual de Feira de Santana, Feira de Santana, 2016. 
VENTURA, Maria Clara Amado Apóstolo et al. O bom professor: opinião dos estudantes. Rev. Enf. Ref., Coimbra, v. III, n. 5, p. 95102, dez. 2011. Disponivel em: http://Www. scielo.mec.pt/scielo.php?script=sci_arttext\&pi$\underline{d=S 0874-02832011000300010 \& \operatorname{lng}=\text { pt\&nrm=iso. }}$. Acesso em: 07 mar. 2019

VERAS, Renata da Silva; FERREIRA, Sandra Patrícia Ataide. A afetividade na relação professor-aluno e suas implicações na aprendizagem, em contexto universitário. Educar em Revista, set.-dez. 2010. Disponivel em: http://www.redalyc.org/articulo. oa?id=155018477015. Acesso em: 7 maio 2019.

\section{Alexsandra de Santana Soares Silva}

Mestranda em Educação pela Universidade Estadual de Feira de Santana (UEFS, Feira de Santana, BA, Brasil).

\section{Marinalva Lopes Ribeiro}

Professora plena do Departamento de Educação da Universidade Estadual de Feira de Santana (UEFS, Feira de Santana, BA, Brasil) e professora permanente do Programa de Pós-Graduação em Educação da UEFS.

\section{Endereço para correspondência}

Alexsandra de Santana Soares Silva

Universidade Estadual de Feira de Santana

Rua Rubens Francisco Dias, 100, Azul Ville, casa 146

44059370

Feira de Santana, BA, Brasil

Marinalva Lopes Ribeiro

Universidade Estadual de Feira de Santana

Rua Barão do Rio Branco, 477, 01

Serraria Brasil, 44003054

Feira de Santana, BA, Brasil 